\title{
Lipid synthesis and secretion in HepG2 cells is not affected by ACTH
}

\author{
Maria Skoog, Maria Berggren-Söderlund, Peter Nilsson-Ehle and Ning Xu*
}

\begin{abstract}
Apolipoprotein B (apoB) containing lipoproteins, i.e. VLDL, LDL and Lp(a), are consequently lowered by ACTH treatment in humans. This is also seen as reduced plasma apoB by $20-30 \%$ and total cholesterol by 30-40\%, mostly accounted for by a decrease in LDL-cholesterol. Studies in hepatic cell line (HepG2) cells showed that apoB mRNA expression is reduced in response to ACTH incubation and is followed by a reduced apoB secretion, which may hypothesize that ACTH lowering apoB containing lipoproteins in humans may be mediated by the inhibition of hepatic apoB synthesis. This was recently confirmed in vivo in a human postprandial study, where ACTH reduced transient apoB48 elevation from the small intestine, however, the exogenic lipid turnover seemed unimpaired. In the present study we investigated if lipid synthesis and/or secretion in HepG2 cells were also affected by pharmacological levels of ACTH to accompany the reduced apoB output. HepG2 cells were incubated with radiolabelled precursors $\left(\left[{ }^{14} \mathrm{C}\right]\right.$ acetate and $\left[{ }^{3} \mathrm{H}\right]$ glycerol) either before or during ACTH stimuli. Cellular and secreted lipids were extracted with chloroform:methanol and separated by the thin layer chromatography (TLC), and $\left[{ }^{14} \mathrm{C}\right]$ labelled cholesterol and cholesteryl ester and $\left[{ }^{3} \mathrm{H}\right]$ labelled triglycerides and phospholipids were quantitated by the liquid scintillation counting. It demonstrated that ACTH administration did not result in any significant change in neither synthesis nor secretion of the studied lipids, this regardless of presence or absence of oleic acid, which is known to stabilize apoB and enhance apoB production. The present study suggests that ACTH lowers plasma lipids in humans mainly mediated by the inhibition of apoB synthesis and did not via the reduced lipid synthesis.
\end{abstract}

\section{Introduction}

ACTH (adrenocorticotrophic hormone) is primary involved in the regulation of steroid hormone synthesis in the adrenal gland [1,2]. When ACTH is administered exogenous it has proven to have positive function on neurological diseases such as infantile spasms and multiple sclerosis $[3,4]$. Over the last decade we have demonstrated that ACTH also has beneficial effects on lipid profile that is not accounted for by the induction of steroid hormone synthesis. ACTH systematically lowers all lipoproteins containing apolipoprotein (apo) B, i.e. very lowdensity lipoprotein (VLDL), low-density lipoprotein (LDL) and Lipoprotein (a), while high-density lipoprotein (HDL) rather is elevated [5]. Further a pronounced and consistent decrease of plasma total cholesterol in particular LDL-cholesterol by $30-40 \%$ is seen after ACTH treatment in healthy individuals and in patients with

* Correspondence: ning.xu@med.lu.se

1 Section of Clinical Chemistry \& Pharmacology, Institute of Laboratory Medicine, Lunds University, S-221 85 Lund, Sweden

Full list of author information is available at the end of the article secondary hyperlipidemia [5-9]. Plasma phospholipids are also significantly reduced and triglycerides are mainly lowered, especially in patients with initially high levels [5,6,8-10].

Studies in vitro, in the HepG2 cell line, indicated that output of apoB and not elimination of apoB containing lipoproteins, via the liver, was the effect of ACTH. Thus, at 10 times physiological level, ACTH significantly and selectively suppresses apoB mRNA levels and apoB secretion, while the receptor mediated uptake of apoB containing lipoproteins, via the LDL receptor or scavenger receptor-BI, or the mRNAs of these receptors were unchanged [11]. The hypothesis that ACTH reduced apoB output was further supported in vivo, by using the human postprandial phase to study the induced apoB48 production. In healthy humans ACTH significantly inhibited the transient rise in apoB48 in plasma, while the lipid handling, followed as triglycerides and retinyl palmitate, seemed unimpaired [10]. We hypothesised that $\mathrm{ACTH}$ induced the intestinal cells to produce larger, 
more lipid rich, but fewer lipoproteins. To see if this is the case also in hepatic cells we herein studied the effects of $\mathrm{ACTH}$ on lipid handling i.e. synthesis and secretion in liver cell cultures where we know apoB output is reduced in response to $\mathrm{ACTH}$.

\section{Materials and methods Materials}

RPMI 1640 with L-glutamine, fetal calf serum (FCS), penicillin/streptomycin (10000 units/mL/10000 $\mu \mathrm{g} / \mathrm{mL})$ and trypsin-EDTA were obtained from Life Technologies. The hepatoblastoma cell line HepG2 was obtained from the American Type Culture Collection, Manassas, VA. Vented cell culture flasks, $25-\mathrm{cm}^{2}$ were from Nunc, Denmark. ACTH1-39 (porcine pituitary), oleic acid (OA), human serum albumin (HSA) and bovine serum albumin (BSA) were from Sigma. ACTH1-24 (Synacthen) was from Novartis and Insulin (Actrapid) was from Novo Nordisk. $\left[1-{ }^{14} \mathrm{C}\right]$ acetate (acetic acid-sodium salt, specific activity $57,0 \mathrm{mCi} / \mathrm{mmol}$ ) and $\left[2-{ }^{3} \mathrm{H}\right]$ glycerol (specific activity $1 \mathrm{Ci} / \mathrm{mmol}$ ) was from Amersham Pharmacia Biotech and scintillation liquid (OptiFluor) was from Perkin Elmer. Thin layer chromatograph plates, aluminium sheets with silica gel 60, were from Merck. Internal standards cholesterol, cholesteryl oleate, phosphatidylcholine and glyceryl trioleate was from Sigma. All other chemicals and solvents used were of analytical grade.

\section{Cell culture conditions}

Stock cultures of HepG2 were kept in $25-\mathrm{cm}^{2}$ flasks under basal conditions. RPMI 1640 complemented with 100 units $/ \mathrm{mL}$ penicillin and $100 \mu \mathrm{g} / \mathrm{mL}$ streptomycin and standard culture conditions $\left(5 \% \mathrm{CO}_{2}, 37^{\circ} \mathrm{C}\right)$, with $10 \%$ FCS present. Medium was changed every second to third day. Cells were subcultured every seventh day, just prior to reaching confluence, into new stock culture and to experimental cultures. Cells were only used up to 20-25 subcultures and were regular controlled for mycoplasma presence. Into each experimental flask $\left(25 \mathrm{~cm}^{2}\right) 3 \times$ $10^{5} \mathrm{cells} / \mathrm{mL}$ were seeded. Medium was changed every second to third day and between incubations with different experimental media cells were washed twice with phosphate-buffered saline (PBS). During all the experiments cells were subconfluent and all experimental media contained penicillin/streptomycin and FCS was substituted with 0,5\% HSA. Basal experimental media contained $0,4 \mathrm{mM}$ oleic acid if not mentioned otherwise. Oleic acid is suggested to increase stability of apoB and hence increase synthesis of apoB containing lipoproteins [12]. Briefly, oleic acid (dried under nitrogen) and HSA (water solution), molar ratio 20:1, was strongly vortexed and was inversed over night at $8^{\circ} \mathrm{C}$. The suspension was added to experimental media, containing $0,5 \%$ HSA, to obtain the final ratio 4:1 of oleic acid and HSA.

\section{Assay of lipid synthesis and secretion}

Prelabel studies; HepG2 cells were incubated in experimental medium with radionuclides, $\left[{ }^{14} \mathrm{C}\right]$ acetate $(0,5 \mu \mathrm{Ci} /$ $\mathrm{ml})$ or $\left[{ }^{3} \mathrm{H}\right]$ glycerol $(1 \mu \mathrm{Ci} / \mathrm{ml})$ for $20 \mathrm{hrs}$. Medium was replaced with experimental medium containing ACTH $(10,100$ or $200 \mathrm{pM}$ Synacthen1-24) or insulin $(1 \mathrm{mg} / \mathrm{ml}$ (170 mM) Actrapid). Continuous labelling; HepG2 cells were preconditioned in the experimental medium with ACTH (100 pM ACTH1-39) for 24 hrs. Medium was replaced with experimental medium containing $\mathrm{ACTH}$ and $\left[{ }^{14} \mathrm{C}\right]$ Acetate $(0,5 \mu \mathrm{Ci} / \mathrm{ml})$ or $\left[{ }^{3} \mathrm{H}\right]$ Glycerol $(1 \mu \mathrm{Ci} / \mathrm{ml})$. During time media samples were collected and stored at $20^{\circ} \mathrm{C}$. After $24 \mathrm{hrs}$ cells were scraped into $1 \mathrm{~mL}$ of PBS.

\section{Extraction and analysis of lipids}

Lipids were extracted from cell and media samples with [chloroform: methanol (1:2; v/v)] [13]. Briefly, step 1: Add [chloroform: methanol (1:2)] to obtain ratio 1:2:1 of [chloroform: methanol: water (sample and $\mathrm{KH}_{2} \mathrm{PO}_{4}, 0,1 \mathrm{M}$, $\mathrm{pH}$ $7,45)]$. Remove upper phase of water-soluble products. Step 2: Add chloroform and $\mathrm{KH}_{2} \mathrm{PO}_{4}$ to obtain ratio 2:1:1 of [chloroform: methanol: water]. Remove upper phase and wash lipid phase with equal volume of [chloroform: methanol: $\mathrm{KH}_{2} \mathrm{PO}_{4}$ (30:480:470)]. The lipid phase was dried under nitrogen gas, dissolved in a small volume of chloroform together with internal standards of unlabeled lipids (cholesterol, cholesteryl oleate, phosphatidylcholine and glyceryl trioleate). The samples were applied onto the TLC plates that were preactivated at $80^{\circ} \mathrm{C}$ over night. Lipids were separated in [petroleumether: diethyl ether: acetic acid $(75: 25: 1 ; \mathrm{v} / \mathrm{v})]$ for $45 \mathrm{~min}$ [14], and were visualised by iodine vapour. The spots were solved in 1 $\mathrm{mL}$ of methanol: water $(1: 1 ; \mathrm{v} / \mathrm{v})$ and counted in $10 \mathrm{~mL}$ of scintillation liquid (OptiFluor) in a beta counter (Rack beta 1214).

\section{Recovery of $\left[{ }^{14} \mathrm{C}\right]$ radioactivity with prelabel design}

After 20 hrs incubation with radioisotope the intracellular activity comprised $40 \%$ of the added activity. Of this cellular activity $83 \%$ is organically solved and after a 24 hrs chase period $81 \%$ is recovered from cells and media as cholesterol, cholesteryl ester, phospholipids, triglycerides and free fatty acids as separated by the TLC.

\section{Analysis of total protein}

Total protein contents of cells were measured according to Lowry [15] with BSA as standard. Cells in PBS were lysed with addition of equal volume of $\mathrm{NaOH}(0,1 \mathrm{M})$. Protein content of cells did not differ between treated and untreated cells.

\section{Statistical analysis}

Results are expressed as mean \pm SD. Data were statistical analysed with GraphPad Prism software. ANOVA was 
used for comparisons of three groups with Bonferroni post-test for selected pairs of columns. Significant difference was established at $\mathrm{p}<0.05$.

\section{Results}

Cells prelabelled with radionuclides were stimulated with ACTH $(10,100$ or $200 \mathrm{pM})$ for $24 \mathrm{hrs}$ and lipids were assessed in media and harvested cells. In the cells the lipid pools of de novo synthesised cholesterol, cholesteryl ester, triglycerides and phospholipids, from the radionuclide precursors, were not affected by the ACTH (Fig. $1 \mathrm{~A})$, and there was no difference between the groups pretreated by different ACTH concentrations (data not shown). Secretion of synthesised radiolabelled lipids at 24 hrs was also unaffected by the ACTH (Fig. 1B). Cells incubated with insulin as a positive control [16] showed a strong significant reduction of secreted lipids at $24 \mathrm{hrs}$, although the cellular pool was not changed. Over the 24hour chase period, after prelabelling, the total output of labelled products into media was increasing, measured as total $\left[{ }^{14} \mathrm{C}\right]$ decays in the media (Fig. $1 \mathrm{C}$ ). ACTH incubation did not alter the output of labelled products, while incubation with insulin showed a significant divergence of de novo labelled material in the media already at $6 \mathrm{hrs}$.
When HepG2 cells had continuous access to lipid precursor, de novo synthesised and secreted lipids are accumulated over time in the media (Fig. 2A-D). The presence of ACTH had no effect on secretion of the radiolabelled lipids, cholesterol, cholesteryl ester, triglycerides and phospholipids, at any time-point even though the cells had been prestimulated with ACTH for $24 \mathrm{hrs}$ as well. In separate experiments under identical conditions, handled in parallel with cells for lipid studies, ACTH reduced apoB mRNA as seen previously (data not shown), this ensured us that the HepG2 cells was responsive to ACTH. Similar to the accumulation of de novo synthesised and secreted lipids with continuous labelling were seen with prelabel design and also then there were no effect of ACTH (Data not shown). Cells allowed to run in experimental medium for $48 \mathrm{hrs}$ (prelabel or continuous label) show almost no further accumulation of labelled lipids in media at $48 \mathrm{hrs}$ compared to $24 \mathrm{hrs}$ regardless of presence of ACTH (Data not shown).

Lipid contents in cells and media have further been studied at 4 and $16 \mathrm{hrs}$ of $\mathrm{ACTH}$ stimulation. There was no obvious effect of ACTH on cellular or secreted labelled lipids at these times intervals as well (Data not shown). Oleic acid was used in the experimental medium


Figure 1 Contents of labelled lipids in cells and culture media. HepG2 cells prelabelled with $\left[{ }^{14} \mathrm{C}\right]$ acetate or $\left[{ }^{3} \mathrm{H}\right]$ glycerol was incubated with $\mathrm{ACTH}$ (200 pM Synacthen) and insulin (1 mg/ml actrapid). Labelled cholesterol, cholesteryl ester, triglyceride and phospholipid, respectively, were evaluated after 24 hrs in cells (A) and media (B). Total secretion of $\left[{ }^{14} \mathrm{C}\right]$ products was followed during the experiment (C). Data represent mean \pm SD of two repeated experiments $(N=11) .{ }^{* *} p<0,01,{ }^{* * *} p<0,001$. 

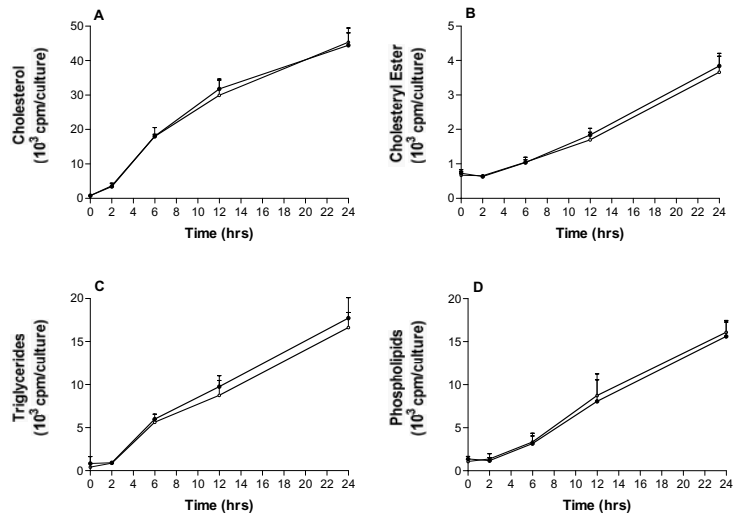

Figure $\mathbf{2}$ Contents of labelled lipids over $\mathbf{2 4}$ hrs. HepG2 cells prestimulated with ACTH (100 pM ACTH1-39) were further incubated with ACTH and [ $\left.{ }^{14} \mathrm{C}\right]$ acetate or $\left[{ }^{3} \mathrm{H}\right]$ glycerol. Labelled cholesterol (A) and cholesteryl ester (B) and triglyceride (C) and phospholipid (D), respectively, were followed during $24 \mathrm{hrs}$ into media. Data represent mean \pm $\mathrm{SD}(\mathrm{N}=6)$.

since it is known to increase stability of apoB and hence increase synthesis of apoB containing lipoproteins [12]. When oleic acid was excluded from the experimental medium there was a change in output of radiolabelled lipids in cells and media, as expected. However, ACTH did not change synthesis or secretion of labelled lipids in the absence of oleic acid either (Fig. 3A and 3B).

\section{Discussion}

In the present study we further confirmed our hypothesis that ACTH lowering apoB containing lipoproteins in humans mainly via the inhibition of hepatic apoB synthesis but not influence cellular lipid synthesis, which is compatible to our recent discovery that lipids was handled just as efficiently regardless of the reduced apoB secretion in response to $\mathrm{ACTH}$ administration, suggest- ing that fewer but more lipid rich lipoproteins are synthesised from the small intestine during $\mathrm{ACTH}$ influence [10].

We have previously reported that ACTH strongly reduce apoB synthesis and secretion, with almost no further accumulation at $48 \mathrm{hrs}$ [11]. This was also seen with secreted lipids in this case, especially with prelabel design, suggesting that lipids and lipoproteins may be subject to recirculation [17]. We have not examined the catabolism of nascent lipoproteins, and the possibility of variation in the reuptake of nascent lipids and lipoproteins cannot be ruled out, however we don't think this mechanism can explain the results seen in this study because ACTH do not affect LDL-receptor mediated uptake or mRNA levels of LDL-receptor and scavenger receptor BI receptor [11]. Further, cells almost reach confluence at $48 \mathrm{hrs}$ of lipid accumulating and thus, several aspects of lipid metabolism may have been altered $[18,19]$. At neither 24 nor 48 hrs did ACTH influenced the cellular lipid pool or lipids secreted in HepG2 cells. Nor was any affect of ACTH on lipid output seen at earlier time points ( 4 or $16 \mathrm{hrs}$ ). Oleic acid was used in the experimental medium due to its ability to stimulate apoB secretion in HepG2 cells by inhibit intracellular apoB degradation [12]. Previously we have showed that oleic acid increased the level of apoB secreted 3-fold in HepG2 cells, however it could not reverse the reduced apoB secretion in response to ACTH [11]. Supplementation of fatty acids stimulates lipid synthesis, in particular triglycerides, though differences in design, such as time and source of fatty acid, yield somewhat different results $[20,21]$. The results we saw in response to oleic acid in this study resembles that of others with increased intracellular triglycerides and greater secretion of cholesterol to cholesteryl ester among other things $[16,22,23]$. Whether oleic acid was present or absent in the experimental
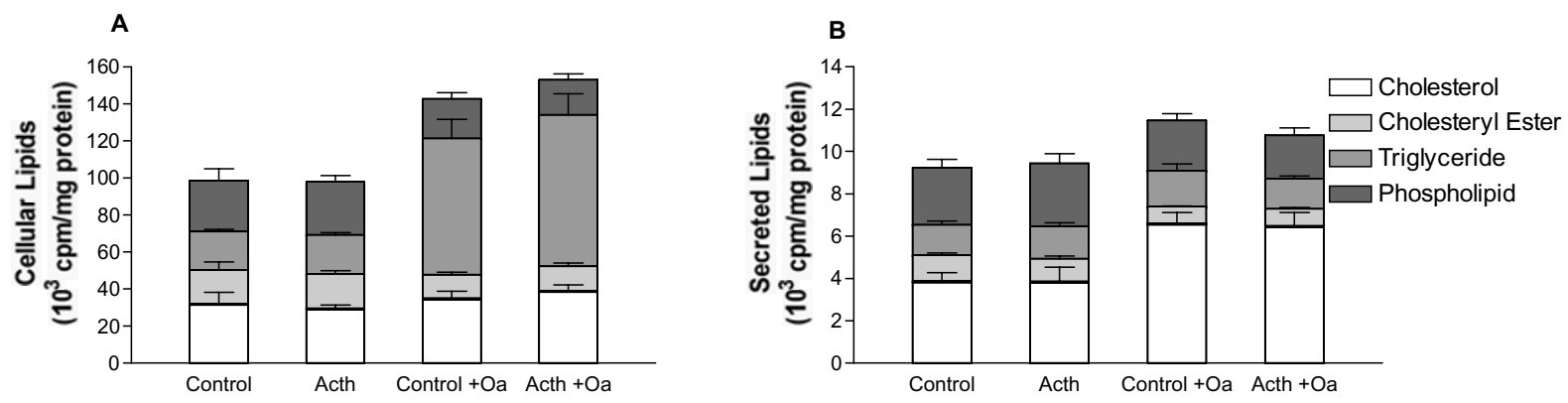

Figure 3 Contents of labelled lipids in cells and media with HSA or HSA-oleic acid. HepG2 cells prelabelled with $\left[{ }^{14} \mathrm{C}\right]$ acetate or $\left[{ }^{3} \mathrm{H}\right] \mathrm{glycerol}$ was incubated with ACTH (200 pM Synecthen) in 0,4 mM Oleic acid bound to HSA (standard conditions) or in only 0,5\% HSA. Labelled cholesterol and cholesteryl ester and triglyceride and phospholipid, respectively, were evaluated after 24 hrs in cells (A) and media (B). Data represent mean \pm SD ( $N$ $=4-6)$. 
medium however did not alter the output of labelled lipids in response to ACTH in HepG2 cells in this study.

The fact that secretion of de novo synthesised lipids was not restrained in parallel with reduced apoB output in HepG2 cells in response to ACTH has also bee seen in the human small intestine in vivo [10]. Although these systems of lipoprotein production may be different the secretory pathway for triglyceride rich lipoproteins in liver and intestine share several characteristics [24-26]. Preliminary results in undifferentiated cultured endothelial cells, Caco2, also support that ACTH do not influence lipid synthesis or secretion directly, but needs to be complemented with studies in polarized cells since they display typical endothelial cell characteristics $[27,28]$. To further study the size and ratio of lipids per apoB of secreted lipoproteins in response to ACTH both in vivo and in vitro is of interest and such studies are initiated.

We know ACTH administration in humans lowers plasma lipids i.e. cholesterol, phospholipids and triglycerides. The hypolipidemic effect includes all apoB-containing lipoproteins, i.e. LDL, VLDL and the atherogenic lipoprotein (a). Generally this can be due to a decreased synthesis or an increased removal of lipoproteins. In HepG2 cells we have demonstrated that ACTH do not influence LDL receptor activity or synthesis, thus do not support an increased elimination of lipoproteins from the liver. Further, we have concluded that catabolism of apoB48 containing chylomicrons was not enhanced by $\mathrm{ACTH}$ in a human postprandial study. All this suggests that catabolism of apoB containing lipoproteins is not the primary way for $\mathrm{ACTH}$ to lower plasma lipids. The finding that ACTH selectively suppress apoB mRNA levels and secretion in HepG2 cells is of great interest and supported by the findings in this study, of no influence on lipid synthesis or secretion, suggests that ACTH primarily act by reducing apoB output, that is the number of lipoproteins, consequently lowering plasma lipids in humans by secondary mechanisms. Studies to gain better understanding of mechanisms by which ACTH actually lowers plasma lipids may have clinical interest since we, to the best of our knowledge, postulate that ACTH lowers plasma lipids by different mechanisms compared to conventional lipid-lowering agents.

\section{Competing interests}

The authors declare that they have no competing interests.

\footnotetext{
Authors' contributions

Conceived and designed the experiments: NX, MBS and PNE. Performed the experiments: MS and NX. Analyzed the data: MS, XN, MBS, and PNE. Wrote the paper: MS, MBS, PNE and NX. All authors read and approved the final manuscript.

\section{Acknowledgements}

This research project was supported by the Swedish Research Council (04966), Swedish Heart-Lung foundation, the Physiographic Society of Lund, the Medical Faculty and Lund University Hospital.
}

\section{Author Details}

Section of Clinical Chemistry \& Pharmacology, Institute of Laboratory Medicine, Lunds University, S-221 85 Lund, Sweden

Received: 19 March 2010 Accepted: 17 May 2010 Published: 17 May 2010

\section{References}

1. Boggaram $V$, Funkenstein B, Waterman MR, Simpson ER: Lipoproteins and the regulation of adrenal steroidogenesis. Endocr Res 1984, 10(34):387-409.

2. Alfano J, Pedersen RC, Kramer RE, Brownie AC: Cholesterol metabolism in the rat adrenal cortex: acute temporal changes following stress. Can J Biochem Cell Biol 1983, 61(7):708-713

3. Brunson KL, Avishai-Eliner S, Baram TZ: ACTH treatment of infantile spasms: mechanisms of its effects in modulation of neuronal excitability. Int Rev Neurobiol 2002, 49:185-197.

4. Filippini G, Brusaferri F, Sibley WA, Citterio A, Ciucci G, Midgard R, Candelise $\mathrm{L}$ : Corticosteroids or ACTH for acute exacerbations in multiple sclerosis. Cochrane Database Syst Rev 2000:CD001331.

5. Berg AL, Nilsson-Ehle P: Direct effects of corticotropin on plasma lipoprotein metabolism in man--studies in vivo and in vitro. Metabolism 1994, 43(1):90-97.

6. Arnadottir M, Berg AL, Dallongeville J, Fruchart JC, Nilsson-Ehle P: Adrenocorticotrophic hormone lowers serum Lp(a) and LDL cholesterol concentrations in hemodialysis patients. Kidney Int 1997, 52(6):1651-1655.

7. Arnadottir M, Dallongeville J, Nilsson-Ehle P, Berg AL: Effects of shortterm treatment with corticotropin on the serum apolipoprotein pattern. Scand J Clin Lab Invest 2001, 61(4):301-306.

8. Berg AL, Nilsson-Ehle P: ACTH lowers serum lipids in steroid-treated hyperlipemic patients with kidney disease. Kidney Int 1996, 50(2):538-542.

9. Berg AL, Nilsson-Ehle P, Arnadottir M: Beneficial effects of ACTH on the serum lipoprotein profile and glomerular function in patients with membranous nephropathy. Kidney Int 1999, 56(4):1534-1543.

10. Skoog M, Xu N, Berggren-Soderlund M, Lovegrove JA, Nilsson-Ehle P. $\mathrm{ACTH}$ reduces the rise in ApoB-48 levels after fat intake. Atherosclerosis 2007, 191(2):433-439.

11. Xu N, Ekstrom U, Nilsson-Ehle P: ACTH decreases the expression and secretion of apolipoprotein B in HepG2 cell cultures. J Biol Chem 2001 276(42):38680-38684

12. Dixon JL, Furukawa S, Ginsberg HN: Oleate stimulates secretion of apolipoprotein B-containing lipoproteins from Hep G2 cells by inhibiting early intracellular degradation of apolipoprotein B. J Biol Chem 1991, 266(8):5080-5086.

13. Bligh EG, Dyer WJ: A rapid method of total lipid extraction and purification. Can J Biochem Physio/ 1959, 37(8):911-917.

14. Nilsson A: Effects of anti-microtubular agents and cycloheximide on the metabolism of chylomicron cholesteryl esters by hepatocyte suspensions. Biochem J 1977, 162(2):367-377.

15. Lowry OH, Rosebrough NJ, Farr AL, Randall RJ: Protein measurement with the Folin phenol reagent. J Bio/ Chem 1951, 193(1):265-275.

16. Dashti N, Wolfbauer G: Secretion of lipids, apolipoproteins, and lipoproteins by human hepatoma cell line, HepG2: effects of oleic acid and insulin. J Lipid Res 1987, 28(4):423-436.

17. Williams KJ, Brocia RW, Fisher EA: The unstirred water layer as a site of control of apolipoprotein B secretion. J Biol Chem 1990, 265(28):16741-16744.

18. Gal D, MacDonald PC, Porter JC, Smith JW, Simpson ER: Effect of cell density and confluency on cholesterol metabolism in cancer cells in monolayer culture. Cancer Res 1981, 41(2):473-477.

19. Jensen E, Floren $\mathrm{CH}$, Nilsson A: Cell density dependent uptake of LDL in cultured rat hepatocytes. Biochim Biophys Acta 1985, 834(2):279-283.

20. Pullinger CR, Gibbons GF: A biphasic effect of exogenous oleate on the rate of cholesterol biosynthesis by rat hepatocytes. Biochem Biophys Res Commun 1981, 99(1):37-43

21. Dashti N, Feng Q, Franklin FA: Long-term effects of cis and trans monounsaturated (18:1) and saturated (16:0) fatty acids on the synthesis and secretion of apolipoprotein A-I- and apolipoprotein Bcontaining lipoproteins in HepG2 cells. J Lipid Res 2000 41(12):1980-1990. 
22. Moberly JB, Cole TG, Alpers DH, Schonfeld G: Oleic acid stimulation of apolipoprotein B secretion from HepG2 and Caco-2 cells occurs posttranscriptionally. Biochim Biophys Acta 1990, 1042(1):70-80.

23. Pullinger $C R$, North JD, Teng BB, Rifici VA, Ronhild de Brito AE, Scott J: The apolipoprotein B gene is constitutively expressed in HepG2 cells: regulation of secretion by oleic acid, albumin, and insulin, and measurement of the mRNA half-life. J Lipid Res 1989, 30(7):1065-1077.

24. Davidson NO, Shelness GS: APOLIPOPROTEIN B: mRNA editing, lipoprotein assembly, and presecretory degradation. Annu Rev Nutr 2000, 20:169-193.

25. Hussain MM: A proposed model for the assembly of chylomicrons. Atherosclerosis 2000, 148(1):1-15.

26. Shelness GS, Sellers JA: Very-low-density lipoprotein assembly and secretion. Curr Opin Lipidol 2001, 12(2):151-157.

27. Jindrichova S, Novakova O, Bryndova J, Tvrzicka E, Lisa V, Novak F, Pacha J: Corticosteroid effect on Caco-2 cell lipids depends on cell differentiation. J Steroid Biochem Mol Biol 2003, 87(2-3):157-165.

28. Levy E, Mehran M, Seidman E: Caco-2 cells as a model for intestinal lipoprotein synthesis and secretion. Faseb J 1995, 9(8):626-635.

doi: $10.1186 / 1476-511 X-9-48$

Cite this article as: Skoog et al., Lipid synthesis and secretion in HepG2 cells is not affected by ACTH Lipids in Health and Disease 2010, 9:48

Submit your next manuscript to BioMed Central and take full advantage of:

- Convenient online submission

- Thorough peer review

- No space constraints or color figure charges

- Immediate publication on acceptance

- Inclusion in PubMed, CAS, Scopus and Google Scholar

- Research which is freely available for redistribution

Submit your manuscript at www.biomedcentral.com/submit
Ciomed Central 